\title{
The Relationship between Prosocial Behavior and Psychological Well-Being among Undergraduate Students
}

\author{
Siti Nurmaizurah Rosli, Asma Perveen
}

To Link this Article: http://dx.doi.org/10.6007/IJARBSS/v11-i6/10119

DOI:10.6007/IJARBSS/v11-i6/10119

Received: 01 April 2021, Revised: 04 May 2021, Accepted: 19 May 2021

Published Online: 01 June 2021

In-Text Citation: (Rosli \& Perveen, 2021)

To Cite this Article: Rosli, S. N., \& Perveen, A. (2021). The Relationship between Prosocial Behavior and Psychological Well-Being among Undergraduate Students. International Journal of Academic Research in Business and Social Sciences, 11(6), 276-289.

\section{Copyright: @ 2021 The Author(s)}

Published by Human Resource Management Academic Research Society (www.hrmars.com)

This article is published under the Creative Commons Attribution (CC BY 4.0) license. Anyone may reproduce, distribute, translate and create derivative works of this article (for both commercial and non-commercial purposes), subject to full attribution to the original publication and authors. The full terms of this license may be seen at: http://creativecommons.org/licences/by/4.0/legalcode

Vol. 11, No. 6, 2021, Pg. 276 - 289

Full Terms \& Conditions of access and use can be found at http://hrmars.com/index.php/pages/detail/publication-ethics 


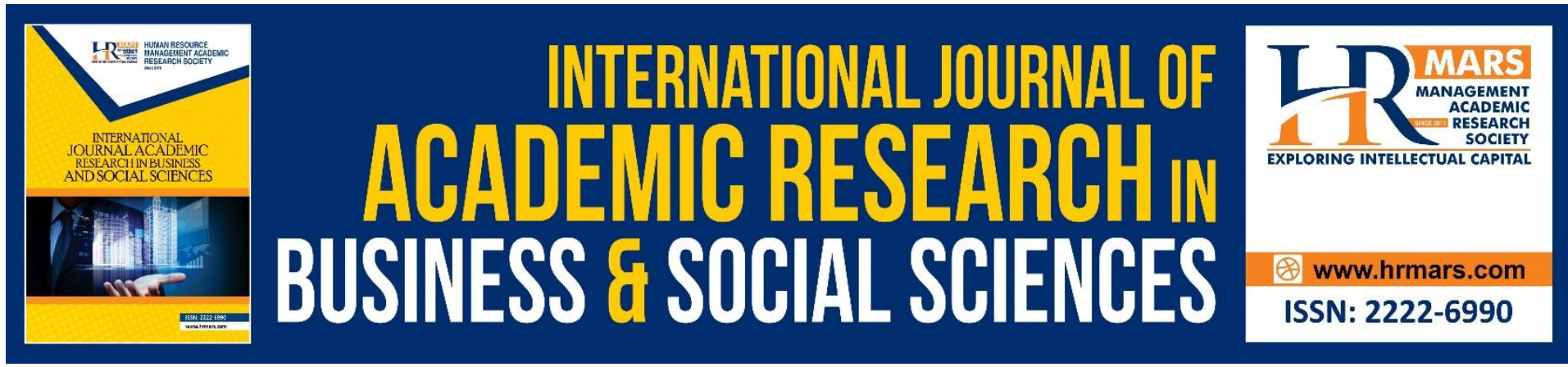

\title{
The Relationship between Prosocial Behavior and Psychological Well-Being among Undergraduate Students
}

\author{
Siti Nurmaizurah Rosli, Asma Perveen \\ Sultan Idris Education University Malaysia
}

\begin{abstract}
This study aimed to provide understanding on the significance of prosocial behavior and psychological well-being among undergraduate students of Sultan Idris Education University (UPSI). Undergraduate students ( $N=156)$ among 48 males and 108 females involved in this study. This is a quantitative study that use online survey method to obtain the data. The participants involved completed a set of questionnaire that consists of demographic information, Prosocialness Scale for Adults, and Ryff's Scale of Psychological Well-being. The results of present study revealed that there is a positive correlation between prosocial behavior and psychological well-being $(r=.30)$, and also a positive correlation between prosocial behavior and domain of psychological well-being of positive relations with others ( $r$ $=.429$ ) among undergraduate students of UPSI. Additional finding proved that prosocial behavior does have significant effect on psychological well-being of the undergraduate students of UPSI at $p<.000$. These findings were found consistent with several previous studies that have been done in various population and country other than Malaysia. Thus, this study is beneficial for the university across Malaysia to encourage the students to involve in any prosocial behavior in order to enhance their psychological well-being throughout their study time.
\end{abstract}

Keywords: Prosocial Behavior, Psychological Well-Being, Positive Relations With Others, Undergraduate Students, Academic Performance

\section{Introduction}

Psychological well-being serves as one of the important aspect in life as it can lead to adaptive human functioning and positive life experiences (Perez, 2012). Psychological well-being refers to the combination of feeling better and functioning well within oneself (Vinothkumar, 2015). It is not merely refers to the absence of any disease or psychological disorder, but also refers to a state of having a meaningful life, good interaction with others and feeling that life is under own control (Kiefer, 2008). However, several previous studies found declined in psychological well- being in adulthood especially undergraduate students in their first year of study due to many reasons include experiencing psychological distress (Field, Duffy \& Huggins, 2015) and face high demands in academic coursework (McSharry \& Timmins, 2017). University life can be stressful for certain students as they need to adapt with new yet different social interaction 
and educational environment (Panahi et al., 2016). In addition, as a grown up adult, students experiencing loss of supports from school and families, and must rely more on own resources in doing something (Wood et al., 2018). As a result, these situations affect the student's overall well-being which also proved to have effect on student's academic performance (Field, Duffy \& Huggins, 2015). According to Panahi et al. (2016), psychological well-being acts as a foundation for student's academic success and students those have better psychological wellbeing possess better adaptive coping skills to adapt with academic stress (Freire et al., 2016).

Students are encouraged to identify any effective strategies to cope with current demands in order to achieve optimal level of psychological well-being, as well as to achieve satisfactory academic life (Panahi et al., 2016). It is also important to make sure that the students receive necessary support and intervention to maintain good psychological wellbeing, thus enable them to complete their degree successfully (Bewick, Koutsopoulou, Miles, Slaa \& Barkham, 2010). Prosocial behavior is one aspect that can improve psychological wellbeing as there are several past researches proved that engaging in prosocial behavior can enhance psychological well-being in various populations (Nelson et al., 2015; Kumar, 2014). However, most of the studies were conducted in country other than Malaysia as well as among adolescents and older adult population. Based on the reviews, there is lack of current researches focusing on the significance of prosocial behavior and its correlation with psychological well-being specifically among undergraduates population in Malaysia.

Prosocial behavior refers to any voluntary actions that intend to benefits others with no immediate benefits to the helper (Padilla-Walker \& Carlo, 2015). There are many different circumstances that can represent as prosocial behavior including doing small acts of kindness such as helping pick up stuff, as well as more sustained or formal acts like volunteering with charitable organization (Lay \& Hoppmann, 2015). Nevertheless, the terms of prosocial behavior, helping and kindness is interchangeable (Nelson et al., 2015). Prosocial behaviors also have been associated with several positive outcomes in life. However, surprisingly it was also reported declined in prosocial behavior in early adulthood (Padilla-Walker, Carlo \& Memmott-Elison, 2018). Adult people are ages older than 19 years old which most of undergraduate students in Malaysia are in the same age range (World Health Organization, 2013).

Some of past researches used self-determination theory to explain the link between prosocial behavior and psychological well-being (Kindap-Tepe \& Aktas, 2019; Kwok, Chui \& Wong, 2013). As according to self-determination theory, Kwok, Chui and Wong (2013) suggested that well-being will be improved when the behaviors are able to satisfy the three basic psychological needs include autonomy, competence and relatedness. For present study, the psychological need of relatedness was closely related with prosocial behavior as it involves social connection (Martela \& Ryan, 2016; Aknin, Dunn, Sandstrom, \& Norton, 2013). Pavey, Greitemeyer and Sparks (2011) suggested that relatedness may promote prosocial behavior because it involves connection with other people. In addition, according to Ryff's theoretical model of psychological well-being, positive relations with others act as one of the component in psychological well-being. This dimension also was seen to be closed related with prosocial behavior as this behavior involve having connection with other people by providing helps to others (Baron \& Branscombe, 2012). Prosocial behavior was proved leads to promote social connections (Aknin, Dunn, Sandstrom, \& Norton, 2013) and well-being was 
improved resulted from connecting with other people based on a study done by Weinstein and Ryan (2010).

\section{Hypotheses}

Based on the objectives of the study, there are several hypotheses that have been proposed including:

Ho1: There is no significant relationship between prosocial behavior and psychological wellbeing among undergraduate students.

Ho2: $_{0}$ There is no significant relationship between prosocial behavior and domain of psychological well-being of positive relations with others among undergraduate students.

Ho3: Prosocial behavior has no significant effect on psychological well-being among undergraduate students.

\section{Literature Review}

\section{Studies on Prosocial Behavior}

Many studies found positive impacts of prosocial behavior. For example, Raposa, Laws and Ansell (2016) revealed that prosocial behavior helps to reduce the negative effects of stress in everyday life among adult population. The result of the study showed that individuals with higher average prosocial behavior reported had higher positive affect. Prosocial behavior refers to one of the affiliative behavior as it involves social connection with others. The finding of the study also suggested that affiliative behavior act as important aspects that help to cope with stress and prosocial behavior become one of the effective strategies to buffer the negative effect of stress for an individual.

As for study done by Alarcón and Forbes (2017), self-reported prosocial behavior revealed negatively associated with depressive symptoms in a non-clinical adolescent sample. The result suggested that, involve in prosocial behavior may help in reducing the depressive symptoms. However, in contrast, the researcher suggested that no significant association between prosocial behavior and depressive symptoms for the non-clinical adults sample as prosocial behavior was found to be declined during adulthood. The same finding found by Haroz and Murray (2013) conducted a study to examine the role of prosocial behavior in reducing mental health problems. This study was conducted among adolescent who were the survivors of war and displacement with some of them reported to have a history of abduction. The findings consistent with previous study proved that high levels of prosocial behavior were associated with improvement in anxiety and depression symptoms. Other results showed that adolescents who engage in more prosocial behaviors despite of their existing depression and anxiety symptoms may have better psychological outcomes compare to their peers who do not engage in prosocial acts. Additional finding of this study also suggested that prosocial behavior is associated with increased in resilience.

A recent longitudinal research done by Davis et al. (2016) also found negative links between depressive symptoms and prosocial behavior. This study was done among U.S Latino, an ethnic minority youth that may be at risk in experiencing high level of ethnic discrimination which negatively affects their mental health. The findings suggested that 
prosocial behavior may help to strengthen the Latino youth's resilience in dealing with discrimination and in the same time may lead to better psychological adjustment. Same finding found in another longitudinal study done by Padilla-Walker, Laura, Carlo and Nielson (2015) which yielded evidence that depression were negatively associated with prosocial behavior among adolescents. In short, engaging prosocial behavior can lead to decrease in depression.

In different context, Aknin et al. (2013) use a generous spending as one form of prosocial behavior. The result of the study showed that this prosocial behavior is emotional rewarding for the givers. In specific, people will experience happier after spending more to charity. Besides, people will feel happier when involve giving something to their acquaintances especially in a situation that facilitate social connection. The study also demonstrated that prosocial behavior may promote social connection between the giver and recipients which act as the aspect that lead to have good feeling after doing a good deed.

\section{Studies on Prosocial Behavior and Psychological Well-being}

Several studies found a positive association between prosocial behavior and psychological well- being. For example, Kumar (2014) revealed that prosocial behavior does significantly positive correlated with psychological well-being. The finding consistent with previous study conducted by Nelson et al. (2015) revealed that there is strong correlation between prosocial behavior and psychological well-being in their study. The researchers use a six-week randomized experimental study of practicing acts of kindness among undergraduate students in United States and South Korea. The participants were randomly assigned to receive autonomy support messages to perform acts of kindness or being instructed to perform acts of kindness, while the control group was instructed to just focus on their academic coursework. The finding proved that performing kind behavior while receiving autonomy support lead to improve in overall psychological well- being compared to other groups in both countries. In short, autonomous prosocial behavior mediated the positive relationship between prosocial behavior and psychological well-being. This study is culturally applicable as it was conducted in different culture.

However, a contradict finding found in study done by Vinothkumar (2015) yielded evidence that there is no significant relationship between prosocial behavior and psychological well-being in overall. In other hand, the results of the study indirectly revealed that prosocial behavior tendency has a significant positive correlation with self-acceptance which refers to one of the psychological well-being dimension.

Besides, prosocial behavior also was proved to predict and have positive effect on well-being of the doer (Weinstein and Ryan, 2010) with relatedness was proved to act as the mediator. Relatedness refers to having connection with others or experience sense of belonging and attachment with others during doing the prosocial acts (Ryan, 2009). Similar finding found in other study conducted by Wiwad and Aknin (2017) attempt to study the emotional consequences of prosocial acts among the university students proved that prosocial acts do lead to increase in well-being. In specific, recalling the other-focused helping does lead to increase in positive affect of the performer compared to when recalling the selffocused helping behavior. Based on the results, the researchers suggested that prosocial 
behavior is indeed emotional rewarding for the performer especially when involve focusing on benefiting others and not focusing on benefiting oneself after doing the good deed.

Aknin et al. (2013) also examined the causal impact of prosocial behavior on wellbeing among university students. The researchers use prosocial spending as one form of prosocial behavior in this study. The results revealed that prosocial spending was significantly increased the well-being of the performer. Significantly higher in well-being were reported for those who recall a prosocial spending made for someone else compared to those who recall a prosocial spending made for themselves. Additional finding also found that the relationship between prosocial behavior and well-being was significantly positive. Another form of prosocial behavior is volunteering (Afolabi, 2013) and there are several studies conducted proved that volunteering is positively correlated and in the same time can enhance psychological well-being. A study done by Son and Wilson (2012) proved that volunteering can enhance eudemonic well-being which also refers as psychological well-being (Lee \& Taniguchi, 2015). The finding consistent with previous research done by Choi and Kim (2011) which revealed that there was found direct positive effect of volunteering on psychological well-being.

Based on the past researches review, prosocial behavior does provide various benefits across culture, country and population especially can enhance psychological well-being. Most of the previous study focuses on adolescent and older adult, and little study focus on undergraduate student population. Therefore, these studies may help to support the current study to test the hypotheses in examining the association between these variables among undergraduate student specifically in Malaysia.

\section{Method}

\section{Research Design}

Study uses an online survey research design to measure the relationship between variables. A set of questionnaire were converted into an online format in a form of Google Forms and distributed to the targeted samples by sharing the link through any social media platform such as WhatsApp and Instagram. The questionnaire consists of three sections which are Section A seek for the demographic information of the respondents includes gender, age, race and current semester, Section B is Prosocialness Scale for Adults, and Section C is Ryff's Scale of Psychological Well- being Inventory (42-items). First and foremost, an informed consent was attached prior to the instruments to ask for their permission to get involved in the study voluntarily. If the participants agree to participate in the study, they can continue to answer the questionnaire in the next section and may withdraw at any moment. The data collected then will be analyzed by using Statistical Package for Social Sciences (SPSS) software Version 23.

\section{Population and Samples}

A total of $(\mathrm{N}=156)$ undergraduate students (48 males and 108 females) of Sultan Idris Education University (UPSI) participated in this study. Based on previous correlational study, the minimum sample size needed adequate to detect significance between the variables was 138 (Cheuk et al., 2019). This calculation was calculated by using G*Power 3.1.9.4 software (Faul, Erdfelder, Lang, \& Buchner, 2007), with an estimated medium effect size of 0.3, a power of 0.95 and alpha value of 0.05 . The age ranges of the respondents are between 20 to 27 years 
old $(M=22.31, S D=1.328)$ which all the participants involved currently degree students from semester 1 until semester $8(M=5.28, S D=1.755)$. The respondents were selected based on convenient sample as it involved drawing sample that are easily accessible and willing to participate in this study voluntarily.

\section{Measures}

Prosocial behaviors were measured using the Prosocialness Scale for Adults, a scale that consists of 16 items developed by Caprara, Steca, Zelli and Capanna in 2005. The scale uses five-point Likert Scale ranging from 1 (never/almost never true) to 5 (almost always/always true). This instrument is reliable to be used with Cronbach's alpha value .91 (Caprara, Steca, Zelli and Capanna, 2005). While psychological well-being were measured by using the 42 items short version of the Ryff's Scale of Psychological Well-being developed by Carol Ryff in 1989 (Lee \& Taniguchi, 2015). A self-report inventory measure six distinct dimensions of psychological well-being include autonomy, environmental mastery, personal growth, positive relations with others, purpose in life and self-acceptance. This inventory use six-point Likert scale ranging from 1 (strongly disagree) to 6 (strongly agree). This scale is reasonably reliable to be used as it has acceptable internal consistency between the subscales with alpha ranging from .66 to .85 (Villarosa \& Ganotice, 2018).

\section{Analysis}

The data obtained was analyses in a form of standardize frequency norm by using Statistical Package for Social Sciences (SPSS) software Version 23. Based on the objective of the study, Pearson correlation analyses were conducted to study the relationship between prosocial behavior and psychological well-being, and also the relationship between prosocial behavior and the dimension of psychological well-being which is positive relation with others. While, simple linear regression analysis was used to examine the effect of prosocial behavior on psychological well-being.

\section{Result}

\section{Correlation analysis of prosocial behavior and psychological well-being}

From Table 1, the result of Pearson correlation analysis revealed that there is a positive correlation although weak between prosocial behavior and psychological well-being, $r(156)$ $=.30, p<.000$, with two-tailed test. The result showed that there is a linear relationship between these two variables. Thus, this concludes that the first null hypothesis $\left(\mathrm{H}_{0} 1\right)$ of there is no significant relationship between prosocial behavior and psychological well-being is rejected for this study. 
Table 1. Correlation Analysis of Prosocial Behavior and Psychological Well-being

\begin{tabular}{|l|l|l|l|}
\hline \multicolumn{2}{|l|}{} & Prosocial Behavior & Psychological Well-being \\
\hline Prosocial Behavior & Pearson Correlation & 1 & $.300^{* *}$ \\
\cline { 2 - 4 } & $\begin{array}{l}\text { Sig. (2-tailed) } \\
\text { N }\end{array}$ & 156 & .000 \\
\hline $\begin{array}{l}\text { Psychological Well- } \\
\text { being }\end{array}$ & Pearson Correlation & $.300^{* *}$ & 1 \\
\cline { 2 - 4 } & $\begin{array}{l}\text { Sig. (2-tailed) } \\
\text { N }\end{array}$ & $\begin{array}{l}.000 \\
156\end{array}$ & 156 \\
\hline \multirow{2}{*}{$* *$ Correlation is significant at the 0.01 level (2-tailed). } & \\
\hline
\end{tabular}

Correlation analysis between prosocial behavior and psychological well-being domain of positive relations with others

Based on Table 2, the result of Pearson correlation analysis revealed that prosocial behavior and positive relations with others dimension have weak positive correlation, $r_{(156)}=.429, p<$ .000 , with two-tailed test. Because of there is correlation between these two variables, hence, the second null hypothesis $\left(\mathrm{H}_{0} 2\right)$ proposed in this research that there is no significant relationship between prosocial behavior and domain of psychological well-being of positive relations with others among undergraduate students is rejected.

Table 2. Correlation Analysis between Prosocial Behavior and Psychological Well-being domain of Positive Relations with Others

\begin{tabular}{|l|l|l|l|}
\hline \multicolumn{2}{|l|}{} & Prosocial Behavior & \multicolumn{1}{|c|}{$\begin{array}{c}\text { Positive Relations with } \\
\text { Others domain }\end{array}$} \\
\hline Prosocial Behavior & Pearson Correlation & 1 & $.429^{* *}$ \\
\cline { 2 - 4 } & $\begin{array}{l}\text { Sig. (2-tailed) } \\
\text { N }\end{array}$ & 156 & $\begin{array}{l}.000 \\
156\end{array}$ \\
\hline $\begin{array}{l}\text { Positive Relations with } \\
\text { Others domain }\end{array}$ & Pearson Correlation & $.429^{* *}$ & 1 \\
\cline { 2 - 4 } & Sig. (2-tailed) & .000 & 156 \\
\hline
\end{tabular}

\section{Regression Analysis of Prosocial Behavior and Psychological Well-being}

In order to predict the effect of prosocial behavior on psychological well-being, a simple linear regression was conducted to test the third hypothesis $\left(\mathrm{H}_{0} 3\right)$ of the study which is prosocial behavior has no significant effect on psychological well-being. Based on the result presented in Table 3 and Table 4, a significant regression equation was found, $F(1,154)=15.282, p<$ .000 , with $R^{2}$ of .090 . It indicates that the predictor explained by $9 \%$ of the variance. To conclude, prosocial behavior $(B=110.966, p<.000)$ were significantly have effect and predict psychological well-being. Therefore, the third null hypothesis of this study was $\left(\mathrm{H}_{0} 3\right)$ rejected. 
Table 3. Regression Analysis of Prosocial Behavior and Psychological Well-being

\begin{tabular}{|l|l|l|l|l|}
\hline \multicolumn{1}{|c|}{ Model } & \multicolumn{1}{|c|}{$\mathbf{R}$} & \multicolumn{1}{c|}{$\mathbf{R}^{\mathbf{2}}$} & \multicolumn{1}{c|}{ Adjusted R } & SE \\
\hline 1 & $.300^{\mathrm{a}}$ & .090 & .084 & 19.89741 \\
\hline \multicolumn{2}{|l|}{ a. Predictors: (Constant), Prosocial Behavior } \\
\hline
\end{tabular}

Table 3. Regression Analysis of Prosocial Behavior and Psychological Wel-being

\begin{tabular}{|c|l|l|l|l|l|l|}
\hline Source & & \multicolumn{1}{c|}{ SS } & \multicolumn{1}{c|}{ Df } & \multicolumn{1}{c|}{ MS } & F & p \\
\hline 1 & Regression & 6050.245 & 1 & 6050.245 & 15.282 & $.000^{\mathrm{b}}$ \\
\hline & Residual & 60969.653 & 154 & 395.907 & & \\
\hline & Total & 67019.897 & 155 & & & \\
\hline \\
$\begin{array}{l}\text { a. Dependent Variable: Psychological Well-being } \\
\text { Predictors: (Constant), Prosocial Behavior }\end{array}$
\end{tabular}

\section{Discussion}

\section{The relationship between prosocial behavior and psychological well-being}

The current study examined whether prosocial behavior have correlation with psychological well-being among undergraduate students and results obtained suggested that there is a positive correlation between those two even though the result showed a weak correlation. This study proved that prosocial behavior does have relationship with psychological wellbeing which consistent with several previous studies conducted in various populations (Nelson et al., 2015; Kumar, 2014; Lay \& Hoppmann, 2015).

However, current finding contradicts with a study done by Vinothkumar (2015) as the researcher found evidence that there is no significant relationship between prosocial behavior and psychological well-being. However, the scale used was different from present study to measure the prosocial behavior, as well as the targeted population is different. These might contribute to have different finding. The researcher also suggested that prosocial behavior might be declined due to experience multiple changes during life transition as well as was found declined in early adulthood in various study (Alarcón \& Forbes, 2017; PadillaWalker, Carlo \& Memmott-Elison, 2018). Therefore, it should be consider that the level of prosocial behavior might be different across ages which then affect its relationship with psychological well-being.

The Relationship between Prosocial Behavior and Psychological Well-being Domain of Positive Relations with Others

As mentioned by Ryff (1989), Ryff's Theoretical Model of Psychological Well-being comprise of six distinct dimensions of psychological well-being include autonomy, environmental mastery, personal growth, purpose in life, positive relations with others, and self-acceptance. Based on this proposed model, positive relations with others domain seems to be close related with prosocial behavior as people are experiencing relatedness through helping others (Caprara, Zelli, Steca \& Capanna, 2005). The result of current study proved this statement by revealed that prosocial behavior does have relationship with positive relations with other domain even though a weak correlation was found. 
Moreover, this finding may prove that having a positive relations and connection with others can act as mediator to correlate the relationship between prosocial behaviors with psychological well-being. This supported by previous study conducted by Weinstein and Ryan (2010) which found relatedness act as mediator on the effect of prosocial behavior on psychological well-being, as well as Aknin et al. (2013) found people will feel happier when doing prosocial acts in a situation that facilitate social connection. Raposa, Laws and Ansell (2016) also suggested that prosocial behavior acts as affiliative behaviors as it involve social connection with others. Hence, these previous findings supported the finding of present study that yielded prosocial behavior does have relationship with domain of psychological wellbeing of positive relations with others.

\section{Effect of Prosocial Behavior and Psychological Well-being}

Even though current finding found there is a correlation between prosocial behavior and psychological well-being, whether these variables have impact on each other should also be investigated because the correlation seems to be weak. Consistent with previous study done in various populations (Weinstein \& Ryan, 2010; Lay \& Hoppmann, 2015), the results of present study showed quantitative evidence to demonstrate the significant effect of prosocial behavior on psychological well-being among undergraduate students of UPSI.

In addition, prosocial behavior was found to have many positive impact in various aspect of life include reduced the depressive symptoms (Alarcón \& Forbes, 2017; Davis et al., 2016), reduced in anxiety symptoms (Haroz et al., 2013), and last but not least is emotional rewarding in a positive way for the giver (Aknin et al., 2013). Positive benefits of prosocial behavior for an individual might also seem to enhance individual's psychological well-being in the same time, which was proved in present study. Therefore, the finding of current study may contribute to the list of positive effect of engaging in prosocial behavior for an individual especially for undergraduate students in Malaysia.

Effect of prosocial behavior on psychological well-being among undergraduate students specifically in Malaysia, this study sought to fill the gap as most of past studies was done among adolescents and older adults especially in other country than Malaysia. In short, prosocial behavior was proved significantly predict psychological well-being in this population. Any university in Malaysia might benefits from this study in the process of providing suitable intervention to improve and maintain students' psychological well-being as it seems essential for overall academic performance throughout their study time (Ansari, Al-Eraky \& Yasmeen, 2019). Having better psychological well-being may lead to perform better in academic performance and also help in individual's development (Panahi et al., 2016).

\section{Limitation and Future Research}

Current study relies only on self-report measures to examine both prosocial behavior and psychological well-being of the participants. This might give chances for social desirability from the participants, as they might not answer the instruments truthfully (Kindap-Tepe \& Aktas, 2019). Therefore, to cater this limitation, future research recommendation should consider the uses of multiple methods such as experiment, observation or any face-to-face method to measure the variables (Padilla-Walker, Carlo \& Memmott-Elison, 2018). Moreover, non-translation of scales used into Malays version can also be a limitation. Although previous 
studies demonstrated that the English version of both scale can be use universally across country, some of the terms might be foreign and ambiguous for certain individuals. Most of Malaysian students use Malay language as their main language, but the measures used in this study are all in English. Thus, some participants might not understand certain words and answer the questionnaires based on their understanding which then affect the total score. Future study should consider translating the instruments into a Malay version and make a pilot test to make sure the instrument is reasonably valid and reliable to be used in Malaysian population. If possible, provide both English and Malay version of the instruments, and make the participant choose based on their preference language (Ganotice Jr, Bernardo \& King, 2012). In addition, this study uses a small size of sample which involved only 156 participants. Plus, the participants were recruited only from one university which might represent selective population of interest that can limit the generalizability of the findings across university especially within Malaysia (Kindap-Tepe \& Aktas, 2019). This would be interesting to conduct such research to replicate the findings among undergraduate students in all universities in Malaysia which then might help to improve Malaysian students' psychological well-being in overall. The need for more longitudinal research regarding prosocial behavior and psychological well-being development across university in Malaysia also seems essential in order to make the findings applicable across years which then help to improve Malaysian society as a whole.

\section{Conclusion}

Present study giving a contribution on the understanding of the importance of prosocial behavior to enhance psychological well-being especially among undergraduate students, as the result reported that engaging more in prosocial behavior lead to have better psychological well-being. In addition, it shows that this positive impact was mediated by having positive connections between the giver and receiver. These provide evidence that prosocial behavior is essential for an individual in order to function well in life especially for the students, which in the same time can improve their social and also interpersonal skills that might benefits them in the future.

Therefore, it is important to provide awareness on the importance of engaging in prosocial behavior to the undergraduate students as it might help to improve and maintain their psychological well-being throughout their study time. University or any institution of higher education might benefits from this study to plan for effective interventions or platform to promote students' well-being (Jafari, 2017). As for example encourage the students to involve in any form of prosocial behavior. The university also may use this study to plan for future research and evaluate the impact of these aspects on academic success or additional skills that might be useful in future, plus provide awareness regarding this topic to all university in Malaysia.

\section{Acknowledgement}

We would like to thank to Department of Human Development of Sultan Idris Education University (UPSI) that have helped with the assistance in completing this research.

\section{Corresponding Author}

Asma Perveen, Sultan Idris Education University, Malaysia.

Email: asmaperveen@fpm.upsi.edu.my 


\section{References}

Aknin, L. B., Dunn, E. W., Sandstrom, G. M., \& Norton, M. I. (2013). Does social connection turn good deeds into good feelings?: On the value of putting the 'social' in prosocial spending. International Journal of Happiness and Development, 1(2), 155-171.

Alarcón, G., \& Forbes, E. E. (2017). Prosocial behavior and depression: A case for developmental gender differences. Current behavioral neuroscience reports, 4(2), 117127.

Ansari, S. K., Al-Eraky, M., \& Yasmeen, R. (2019). Medical students' psychological wellbeing and their overall academic performance - a correlational study. Pakistan Journal of Physiology, 15(2), 84-88.

Baron, R. A., Byrne, B., \& Branscombe, N. R. (2012). Social psychology 13th ed.

Bewick, B., Koutsopoulou, G., Miles, J., Slaa, E., \& Barkham, M. (2010). Changes in undergraduate students' psychological well-being as they progress through university. Studies in Higher Education, 35(6), 633-645.

Caprara, G. V., Zelli, A., Steca, P., \& Capanna, C. (2005). A new scale for measuring adult's prosocialness. European Journal of Psychological Assessment, 21(2), 77-89. DOI 10.1027/1015-5759.21.2.77.

Cheuk, K. Y., Hu, Y., Tam, E. M., Shi, L., Fiona, W. P., Hung, V. W., ... \& Ng, B. K. (2019). Bone measurements at multiple skeletal sites in adolescent idiopathic scoliosis - an in vivo correlation study using DXA. HR- pQCT and QCT. Archives of osteoporosis, 14(1), 70.

Choi, N. G., \& Kim, J. (2011). The effect of time volunteering and charitable donations in later life on psychological wellbeing. Ageing \& Society, 31(4), 590-610.

Davis, A. N., Carlo, G., Schwartz, S. J., Unger, J. B., Zamboanga, B. L., Lorenzo-Blanco, E. I., \& Martinez, M. M. (2016). The longitudinal associations between discrimination, depressive symptoms, and prosocial behaviors in US Latino/a recent immigrant adolescents. Journal of youth and adolescence, 45(3), 457-470.

Faul, F., Erdfelder, E., Lang, A.-G. \& Buchner, A. (2007). G*Power 3: A flexible statistical power analysis program for the social, behavioral, and biomedical sciences. Behavior Research Methods, 39, 175-191.

Field, R., Duffy, J., \& Huggins, A. (2015). Teaching Independent Learning Skills in the First Year: A Positive Psychology Strategy for Promoting Law Student Well-Being. Journal of Learning Design, 8(2), 1-10.

Freire, C., Ferradas, M. D. M., Valle, A., Nunez, J. C., \& Vallejo, G. (2016). Profiles of psychological well-being and coping strategies among university students. Frontiers in psychology, 7, 1554.

Ganotice Jr, F. A., Bernardo, A. B., \& King, R. B. (2012). Testing the factorial invariance of the English and Filipino versions of the Inventory of School Motivation with bilingual students in the Philippines. Journal of Psychoeducational Assessment, 30(3), 298-303.

Haroz, E. E., Murray, L. K. (2013). Adolescents resilience in Northern Uganda: The role of social support and prosocial behavior in reducing mental health problems. Journal of Research on Adolescence, 23(1), 138-148Kiefer, R. A. (2008). An integrative review of the concept of well-being. Holistic Nursing Practice, 22(5), 244-252.

Jafari, M. (2017). Life 101 enhances healthy lifestyle choices in pre-health undergraduate students. Journal of University Teaching \& Learning Practice, 14(3), 4.

Kindap-Tepe, Y., \& Aktas, V. (2019). The Mediating Role of Needs Satisfaction for Prosocial Behavior and Autonomy Support. Current Psychology, 1-13. 
Kumar, R. (2014). Psychological well-being among adolescents: Role of prosocial behavior. Indian Journal of Health and Wellbeing, 5(3), 368.

Kwok, Y. Y., Chui, W. H., \& Wong, L. P. (2013). Need satisfaction mechanism linking volunteer motivation and life satisfaction: A mediation study of volunteers subjective well-being. Social indicators research, 144(3), 1315-1329.

Lay, J. C., \& Hoppmann, C. A. (2015). Altruism and prosocial behavior. Encyclopedia of geropsychology, 5(2015), 1-9.

Lee, H. E., \& Taniguchi, E. (2015). A cross-cultural validation of the six-factor model of psychological well-being. Psycho Well-being, 5, 1-13.

Martela, F., \& Ryan, R. M. (2016). Prosocial behavior increases well-being and vitality even without contact with the beneficiary: Causal and behavioral evidence. Motivation and Emotion, 40(3), 351-357.

McSharry, P., \& Timmins, F. (2017). Promoting healthy lifestyle behaviours and well-being among nursing students. Nursing Standard, 31(24).

Nelson, S. K., Bella Porta, M. D., Jacobs Bao, K., Lee, H. C., Choi, I., Lyubomirsky, S. (2015). 'It's up to you': Experimentally manipulated autonomy support for prosocial behavior improves well-being in two cultures over six weeks. The Journal of Positive Psychology, 10(5), 463-476.

Padilla-Walker, L. M., Carlo, G., \& Nielson, M. G. (2015). Does helping keep teens protected? Longitudinal bidirectional relations between prosocial behavior and problem behavior. Child Development, 86(6), 1759- 1772.

Padilla-Walker, L. M., \& Carlo, G., \& Memmott-Elison, M. K. (2018). Longitudinal change in adolescents' prosocial behavior toward strangers, friends, and family. Journal of Research on Adolescence, 28(3), 698- 710.

Panahi, S., Aida Suraya Md Yunus, Samsilah Roslan, Rusnani Abdul Kadir, Wan Marzuki Wan Jaafar \& Mohammad Saeed Panahi. (2016). Predictors of Psychological Well-being among Malaysian Graduates. Online Submission, 16, 2067-2083.

Pavey, L., Greitemeyer, T., \& Sparks, P. (2011). Highlighting relatedness promotes prosocial motives and behavior. Personality and Social Psychology Bulletin, 37(7), 905-917.

Perez, J. A. (2012). Gender difference in psychological well-being among Filipino college student samples. International Journal of Humanities and Social Science, 2(13), 84-93.

Raposa, E. B., Laws, H. B., \& Ansell, E. B. (2016). Prosocial behavior mitigates the negative effects of stress in everyday life. 4(4), 691-698. DOI: 10.1177/2167702615611073.

Ryff, C. D. (1989). Happiness is everything, or is it? Explorations on the meaning of psychological well-being. Journal of personality and social psychology, 57(6), 1069.

Son, J., \& Wilson, J. (2012). Volunteer work and hedonic, eudemonic, and social well-being. In Sociological Forum, 27(3), 658-681. Oxford, UK: Blackwell Publishing Ltd.

Villarosa, J. B., \& Ganotice, F. A. (2018). Construct validity of Ryff's psychological well-being scale: Evidence from Filipino teachers in the Philippine. Philippines Journal of Psychology, 51(1), 1-20.

Vinothkumar, M. (2015). Adolescence psychological well-being in relation to spirituality and pro-social behavior. Indian Journal of positive Psychology, 6(4), 361-366.

Wiwad, D., \& Aknin, L. B. (2017). Motives matter: The emotional consequences of recalled self-and other-focused prosocial acts. Motivation and Emotion, 41(6), 730-740.

Weinstein, N., \& Ryan, R. M. (2010). When helping helps: autonomous motivation for prosocial behavior and its influence on well-being for the helper and recipient. Journal of personality and social psychology, 98(2), 222. 
Wood, D., Crapnell, T., Lau, L., Bennett, A., Lotstein, D., Ferris, M., \& Kuo, A. (2018). Emerging adulthood as a critical stage in the life course. In Handbook of life course health development (pp. 123-143). Springer, Cham.

World Health Organization. (2013). Definition of key terms: HIV and AIDS. Consolidated ARV guideline, 2013. 